\title{
Sistem Pendukung Keputusan Pemilihan Kayu Di Toko Bangunan Jeruju Permai Dengan Metode SAW Berbasis Web
}

\author{
Andalas Rivaldi Permana ${ }^{1)}$, Yulrio Brianorman ${ }^{2)}$ \\ 1), 2) Fakultas Teknik, Universitas Muhammadiyah Pontianak \\ e-mail: andalas.rivaldi@unmuhpnk.ac.id,y.brianorman@unmuhpnk.ac.id
}

Article history
Received August
26,2020
Revised Okt 17,
2020
Accepted Nov 2,
2020
Available online
Nov 30, 2020
Keywords
Alternative
selection of wood
type, Simple
Additive Weighting
(SAW), Decision
Support System

The Jeruju Permai Building Store is one of the building stores that sells building materials and tools. This shop sells nails, hoes, cement, wood. The Jeruju Permai building store was established in 2013, which was founded by Mr. Didik, this building shop is located on Jalan Komyos Soedarso, Jeruju City of Pontianak. The Jeruju Permai Shop has a mission in selecting wood based on certain criteria set by the Jeruju Permai Building Store. Decision support system is a system used to determine alternatives for selecting the best type of wood that has been determined using the Simple Additive Weighting (SAW) method. The basic concept of the Simple Additive Weighting method is to find the weighted sum of the performance ratings for each alternative on all criteria. The test is carried out with new data (test data) from the alternative. The selection of wood types of test data is normalized according to the type of attribute criteria (benefit or cost). The final result is obtained from the calculation process, which is the sum of normalized matrices with weights per criterion which shows an alternative ranking. Selection of wood species from the closest to the most distant criteria. From there, an alternative is obtained which agent has the best type of wood.

Keywords: Alternative selection of wood type, Simple Additive Weighting (SAW), Decision Support System

\section{Abstrak}

Toko Bangunan Jeruju Permai merupakan salah satu toko bangunan yang menjual bahan dan alat bangunan. Toko ini menjual paku, cangkul, semen, kayu. Toko bangunan jeruju permai berdiri pada tahun 2013 yang didirikan oleh Bapak Didik, toko bangunan ini berlokasi di jalan komyos soedarso, Jeruju kota Pontianak. Toko Jeruju Permai memiliki misi dalam pemilihan kayu berdasarkan kriteria tertentu yang telah ditetap oleh Toko Bangunan Jeruju Permai. Sistem pendukung keputusan merupakan sebuah sistem yang digunakan untuk menentukan alternatif Pemilihan jenis kayu terbaik yang telah ditentukan dengan menggunakan metode Simple Additive Weighting (SAW). Konsep dasar dari metode Simple Additive Weighting ini adalah mencari penjumlahan terbobot dari rating kinerja pada setiap alternatif pada semua kriteria. Pengujian dilakukan dengan data baru (data uji) dari alternatif Pemilihan jenis kayu data uji tersebut dinormalisasi sesuai dengan jenis atribut kriteria (benefit atau cost). Hasil akhir diperoleh dari proses perhitungan, yaitu penjumlahan dari matriks ternormalisasi dengan bobot per kriteria yang menunjukkan rangking alternatif Pemilihan jenis kayu dari yang paling mendekati kriteria hingga yang paling jauh dari kriteria. Dari sana lah didapat alternatif yang agen mana yang memiliki jenis kayu terbaik.Kata Kunci : Penerimaan, Pegawai, waterfall, dan Java.

Kata kunci: Alternatif pemilihan jenis kayu, Simple Additive Weighting (SAW), Sistem Pendukung Keputusan 


\section{Pendahuluan}

Toko Bangunan Jeruju Permai merupakan salah satu toko bangunan yang menjual bahan dan alat bangunan. Toko ini menjual paku, cangkul, semen, kayu. Toko bangunan jeruju permai berdiri pada tahun 2013 yang didirikan oleh Bapak Didik, toko bangunan ini berlokasi di jalan komyos soedarso, Jeruju kota Pontianak. Toko Jeruju Permai memiliki misi dalam pemilihan kayu berdasarkan kriteria tertentu yang telah ditetap oleh Toko Bangunan Jeruju Permai.

Sistem pendukung keputusan (SPK) adalah bagian dari sistem informasi berbasis komputer termasuk sistem berbasis pengetahuan atau menajemen pengetahuan yang dipakai untuk mendukung pengambilan keputusan dalam suatu organisasi atau perusahaan. Dapat juga dikatakan sebagai sistem komputer yang mengolah data menjadi informasi untuk mengambil keputusan dari masalah semi terstruktur yang spesifik ${ }^{[1]}$.

$$
\text { Metode Simple Additive }
$$

Weighting (SAW) merupakan metode penjumlahan terbobot. Konsep dasar metode Simple Additive Weighting (SAW) adalah mencari penjumlahan terbobot dari rating kinerja pada setiap alternatif pada semua kriteria. Metode Simple Additive Weighting (SAW) membutuhkan proses normalisasi matrik keputusan (X) ke suatu skala yang dapat diperbandingkan dengan semua rating alternatif yang ada ${ }^{[2]}$.

\section{Metode Penelitian}

\subsection{Alur Sistem}

Alur sistem yang dibangun dapat dilihat pada gambar berikut :

a. Agen/pemasok kayu mengirimkan jenis foto kayu ke toko bangunan jeruju permai dan telah terdaftar sebagai agen pemasok kayu pada toko bangunan jeruju permai.

b. Setelah jenis foto kayu terkirim ke toko bangunan jeruju permai, admin memasukkan data foto kayu dari agen ke dalam database sistem hingga agen pengirim terakhir.

c. Admin memproses data foto kayu ya (cost) tersebut hingga ke perhitungan
Simple Additive Weighting, dan hasil perhitungan dapat ditampilkan dan disimpan ke database sistem.

d. Admin menampilkan hasil data foto kayu sesuai yang diinginkan toko dari perhitungan sebagai laporan. Dan didapatkan hasil agen yang diajukan sebagai pemasok kayu sesuai dengan jumlah kayu yang ditentukan.

\subsection{Perhitungan Dengan Simple Additive Weighting (SAW)}

Berikut adalah langkah-langkah penghitungan dengan metode Simple Additive Weighting (SAW):

a. Menentukan Alternatif (Ai)

b. Menentukan kriteria yang akan dijadikan acuan dalam pengambilan keputusan $(\mathrm{Cj})$

c. Menentukan bobot preferensi atau tingkat kepentingan (W) setiap kriteria

d. Menentukan Nilai Kecocokan setiap kriteria

e. Membuat matrik keputusan (X) yang didapat dari rating kecocokan pada setiap alternatif (Ai) dengan setiap kriteria $(\mathrm{Cj})$.

f. Melakukan langkah normalisasi matriks keputusan $(\mathrm{X})$ dengan cara menghitung nilai rating kinerja ternormalisasi (rij) dari alternatif (Ai) pada kriteria (Cj) dengan rumus :

$$
r_{i j}=\left\{\frac{x_{i j}}{\operatorname{Max}_{i} x_{i j}}\right\}
$$

(benefit)

Jika $\mathrm{j}$ adalah atribut keuntungan

$$
r_{i j}=\left\{\frac{{ }_{i}^{\operatorname{Min}} x_{i j}}{x_{i j}}\right\}
$$

Jika $\mathrm{j}$ adalah atribut bia 
g. Hasil dari normalisasi (rij) membentuk matrik ternormalisasi (R).

$$
R=\left[\begin{array}{cccc}
r_{11} & r_{12} & \ldots & r_{1 j} \\
\vdots & & & \vdots \\
r_{i 1} & r_{i 2} & \ldots & r_{i j}
\end{array}\right]
$$

h. Hasil akhir nilai preferensi (Vi) diperoleh dari penjumlahan dari perkalian elemen baris matrik ternormalisasi (R) dengan bobot preferensi (W) yang bersesuaian elemen kolom matrik (W).

$$
V_{I}=\sum_{j=1}^{n} w_{j} r_{i j}
$$

Dengan :

alternatif

$\mathrm{Vi}=$ rangking untuk setiap

$\mathrm{wj}=$ nilai bobot dari setiap kriteria

rij $=$ nilai rating kinerja

ternormalisasi.

\section{Rancangan Flowchart Sistem}

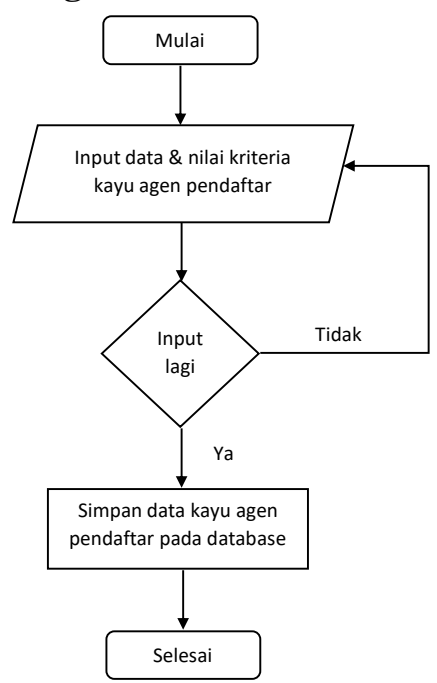

Gambar 1. Flowchart Data kayu

Gambar diatas adalah flowchart data kayu dari toko. Yaitu dengan memasukkan data kayu dari agen pendaftar beserta kriterianya hingga kayu dari agen terakhir terakhir. Jika sudah sampai kayu terakhir maka data akan disimpan pada database.

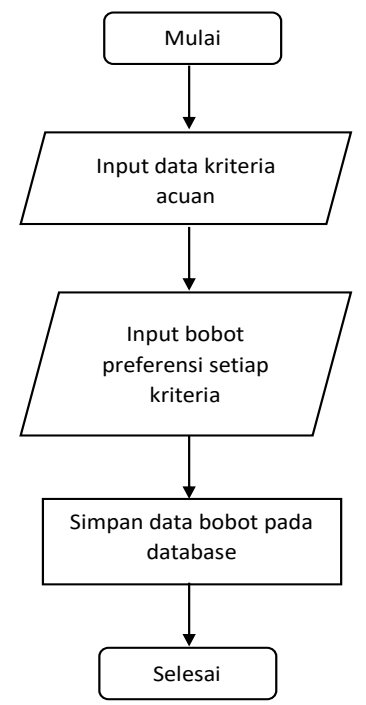

Gambar 2. Flowchart Kriteria Acuan dan Bobot

Pada flowchart kriteria acuan dan bobot, penambahan bobot sesuai dengan kriteria. Yaitu dengan memasukkan data kriteria acuan terlebih dahulu, dan selanjutnya dimasukkan bobot preferensi dari setiap kriteria acuan tersebut. Selanjutnya simpan data bobot pada database.

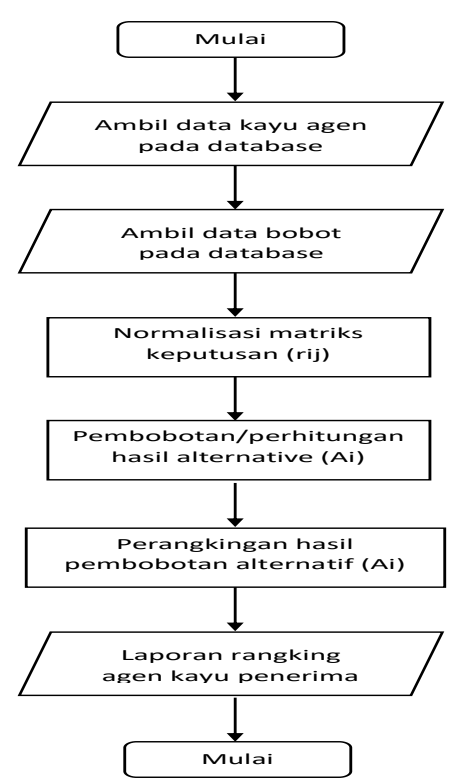

Gambar 3. Flowchart penghitungan SAW

Pada flowchart penghitugan SAW, Langkah awal yaitu mengambil data kayu agen pada database. Data kayu itu adalah 
data yang diperlukan saja sesuai dengan kriteria acuan. Selanjutnya adalah mengambil data bobot masing-masing kriteria acuan dari database. Untuk selanjutnya dilakukan normalisasi data sesuai dengan kriteria acuan (benefit atau cost). Setelah data yang telah dinormalisasi didapatkan, maka dilakukan penghitungan dan didapatkan hasil akhir dari masingmasing alternatif. Selanjutnya hasil tersebut dirangkingkan dari yang terbesar hingga terkecil, agar diketahui agen yang memiliki jenis kayu yang terbaik sesuai dengan keperluan toko.

\section{Hasil dan Pembahasan}

\subsection{Hasil Perhitungan Dengan Data Uji}

Tabel 1. Alternatif Pemilihan Jenis Kayu

\begin{tabular}{|c|c|c|c|c|c|}
\hline \multirow[b]{2}{*}{$\begin{array}{l}\text { Altern } \\
\text { atif }\end{array}$} & \multicolumn{5}{|c|}{ Kriteria } \\
\hline & $\begin{array}{l}\text { Taha } \\
\mathrm{n} \\
\text { Bent } \\
\text { uran }\end{array}$ & $\begin{array}{l}\text { Kandu } \\
\text { ngan } \\
\text { Minya } \\
\text { k }\end{array}$ & $\begin{array}{l}\text { Ser } \\
\text { at }\end{array}$ & $\begin{array}{l}\text { Har } \\
\text { ga }\end{array}$ & $\begin{array}{l}\text { Terse } \\
\text { rang } \\
\text { Ham } \\
\text { a }\end{array}$ \\
\hline $\begin{array}{l}\text { Kayu } \\
\text { Jati }\end{array}$ & 1.00 & 0.80 & $\begin{array}{l}0.9 \\
0\end{array}$ & $\begin{array}{l}0.7 \\
5\end{array}$ & 0.85 \\
\hline $\begin{array}{l}\text { Kayu } \\
\text { Maho } \\
\text { ni }\end{array}$ & 0.80 & 0.60 & $\begin{array}{l}0.7 \\
5\end{array}$ & $\begin{array}{l}0.5 \\
0\end{array}$ & 0.50 \\
\hline $\begin{array}{l}\text { Kayu } \\
\text { Sungk } \\
\text { ai }\end{array}$ & 0.75 & 0.50 & $\begin{array}{l}0.5 \\
0\end{array}$ & $\begin{array}{l}0.4 \\
5\end{array}$ & 0.50 \\
\hline
\end{tabular}

Langkah kedua adalah menentukan kriteria yang akan dijadikan acuan dalam pengambilan keputusan $(\mathrm{Cj})$. Berikut adalah kriteria acuan dalam pemilihan jenis kayu pada toko jeruju permai :

Tabel 2. Kriteria Acuan

\begin{tabular}{ll}
\hline Keterangan & Kriteria $\mathrm{Cj}$ \\
\hline Tahan Benturan & $\mathrm{C} 1$ \\
Kandungan Minyak & $\mathrm{C} 2$ \\
Serat & $\mathrm{C} 3$ \\
Harga & $\mathrm{C} 4$ \\
Terserang Hama & $\mathrm{C} 5$ \\
\hline
\end{tabular}

Selanjutnya adalah menentukan bobot preferensi atau tingkat kepentingan (W) setiap kriteria. Bobot preferensi kriteria yang telah ditentukan adalah $\mathrm{W}=[1,0.75,0.50$, $0.25,0.50]$. Setelah bobot setiap kriteria ditetapkan, maka selanjutnya adalah menentukan nilai kecocokan dari setiap kriteria. Berdasarkan kriteria acuan, ditetapkan nilai kecocokannya adalah sebagai berikut :

Tabel 3. Nilai Kecocokan Kriteria

\begin{tabular}{ll}
\hline Kriteria $\mathrm{Cj}$ & Kecocokan \\
\hline $\mathrm{C} 1$ & Benefit \\
$\mathrm{C} 2$ & Benefit \\
$\mathrm{C} 3$ & Benefit \\
$\mathrm{C} 4$ & Cost \\
$\mathrm{C} 5$ & Cost \\
\hline
\end{tabular}

Langkah selanjutnya adalah melakukan normalisasi matriks keputusan (X) dengan cara menghitung nilai rating kinerja ternormalisasi (rij) dari alternatif (Ai) pada kriteria $(\mathrm{Cj})$ sesuaidengan nilai kecocokannya. Matriks keputusan (W) didapat dari data alternatif Pemilihan jenis kayu agen, yaitu sebagai berikut :

$\begin{array}{lll}1.00 & 0.80 & 0.90 \\ 0.80 & 0.60 & 0.75 \\ 0.75 & 0.50 & 0.50\end{array}$

Kemudian matriks diatas dinormalisasi dengan penghitungan sesuai dengan kecocokan kriteria masing-masing data (benefit/cost). Sehingga terbentuk matrik ternormalisasi $(\mathrm{R})$
1.33
1.33
1.00
1.07
1.00
0.83
1.00
0.83
0.56

Langkah selanjutnya adalah penghitungan hasil akhir nilai preferensi (Vi) yang diperoleh dari penjumlahan dari perkalian elemen baris matrik ternormalisasi (R) dengan bobot preferensi (W) yang 
bersesuaian elemen kolom matrik (W). Dengan perhitungan sebagai berikut :

V1

$(1,00)(1,33)+(0,75)(1,33)+(0,50)(1,00)+(0$,

$25)(0,67)+(0,50)(1,00)=3,50$

$\mathrm{V} 2$

$(1,00)(1,07)+(0,75)(1,00)+(0,50)(0,83)+(0$,

$25)(1,00)+(0,50)(1,70)=3,33$

V3

$(1,00)(1,00)+(0,75)(0,83)+(0,50)(0,56)+(0$, $25)(1,11)+(0,50)(1,70)=3,03$

Jadi, jenis kayu yang dipilih oleh toko jeruju permai dari agen Berada di V1, sehingga alternatif kayu jati (A1) adalah alternatif yang terpilih sebagai alternatif terbaik.

\section{Kesimpulan}

Kesimpulan yang dapat diambil setelah pembuatan sistem pendukung keputusan ini adalah berdasarkan hasil pengujian dengan beberapa alternatif diperoleh kesimpulan bahwa Sistem Pendukung Keputusan Pemilihan jenis kayu pada agen harus sesuai dengan kualitas keperluan suatu bangunan.

Saran-saran untuk pengembangan program ini adalah perlu adanya sosialisasi ke tempat ahli jenis kayu pada toko jeruju permai, agar sistem ini dapat dipergunakan untuk mempermudah pengecekan jenis kayu kualitas. Selain itu, perbaikan dan pengembangan harus terus dilakukan untuk menyempurnakan sistem agar benar-benar sesuai dengan harapan semua pihak.

\section{Referensi}

[1] Ramadhana, Rizka, H, "Sistem Pendukung Keputusan Pemilihan Jurusan pada MAN 1 Banjarmasin Menggunakan Metode Weighted Produk". POLIBAN, Banjarmasin, Indonesia. 2016.

[2] Rinaldhi, Galih Eka, "Penerapan Metode Simple Additive Weighting (SAW) untuk Sistem Pendukung Keputusan Penentuan Pemilihan Beasiswa bantuan Siswa Miskin (BSM) pada SMA Negeri 1 Subah Kab. Batang”, UDN, 2013.
[3] Binarso, F.A.H, 2016 Sistem Pendukung Keputusan Pemilihan Gadget Smartphone Menggunakan Metode Simple Additive Weighting.Skripsi.Universitas Dian Nuwantoro Semarang.

[4] Susanti, Nila., dan Sri Winiarti. 2013. Sistem Pendukung Keputusan Penentuan Kualitas Kayu untuk Kerajinan Mebel. Yogyakarta.

[5] Nisfi, Choirotun., 2012. Skripsi, Sistem Pendukung Keputusan Pemilihan Villa di Objek Wisata Pacet Menggunakan Metode Simple Additive Weighting. Gresik: UMG.

[6] Rusito. (2017). Sistem Pendukung Keputusan Untuk Menentukan Kualitas Kayu Olahan Meggunakan Metode Simple Additive Weighting (Saw). Sistem Pendukung Keputusan,14.

[7] Winoto, A. D. Y. (2014). Kontruksi Kayu Untuk Rumah Dan Bangunan Sederhana. Yogyakarta: TAKA Publisher 